\title{
A gentrificação e a hipótese do diferencial de renda: limites explicativos e diálogos possíveis
}

\author{
Gentrification and the rent gap hypothesis: \\ explanatory limits and possible dialogs
}

Alvaro Luis dos Santos Pereira

\section{Resumo}

Este artigo traz reflexões sobre os processos de gentrificação a partir da combinação de argumentos dos modelos teóricos centrados na oferta com hipóteses dos modelos centrados na demanda. São apontados limites explicativos das interpretações elaboradas a partir da noção de diferencial de renda, destacando-se como aspectos problemáticos à indefinição dos fatores constitutivos daquilo que os autores que abordam a gentrificação a partir desta chave analítica chamam de renda potencial, bem como a indeterminação espacial do campo de incidência desse fenômeno. Sugere-se a articulação entre 0 argumento do diferencial de renda e proposições acerca do conteúdo econômico assumido por fatores simbólicos como forma de se alcançar uma compreensão mais abrangente acerca das causas e da dinâmica territorial dos processos de gentrificação.

Palavras-chave: gentrificação; produção do espaço urbano; diferencial de renda; estetização; valorização.

\begin{abstract}
This article addresses the debate on gentrification based on the combination of arguments originated from supply-side theoretical models and hypotheses derived from demand-side models. It presents explanatory limits of interpretations based on the notion of rent gap, and discusses problematic aspects, such as: the lack of definition of the factors that constitute what the authors who approach gentrification from this perspective call potential land rent, and the spatial indetermination of the field of incidence of gentrification. The articulation between the rent gap argument and the thesis of the commoditization of symbolic features is suggested as a means of achieving a broader understanding of the causes and the territorial dynamics of the gentrification process.
\end{abstract}

Keywords: gentrification; urban space production; rent gap; aestheticization; valorization. 


\section{Introdução}

0 termo "gentrificação" tornou-se uma categoria central para se pensar as transformações vivenciadas nas cidades contemporâneas. Presente em textos acadêmicos, discursos de ativistas e movimentos sociais, e até mesmo em materiais publicitários de agentes do mercado, pode-se dizer que a consciência acerca da difusão do processo representado por essa expressão tornou-se um fenômeno generalizado. $A$ despeito dos diferentes entendimentos quanto às forças motrizes, à dinâmica e ao sentido das transformações urbanas que vêm sendo chamadas de "gentrificação", a expressiva difusão do uso desse termo evidencia por si só uma convergência na percepção de um fenômeno que vem assumindo características semelhantes em diferentes contextos geográficos.

Esse termo foi empregado pela primeira vez num conhecido estudo da socióloga britânica Ruth Glass (1964), que cunhou tal expressão para caracterizar o início de uma onda de invasão dos mews da área central de Londres, tradicionalmente ocupados por classes trabaIhadoras, por novos moradores de classe média e alta. A expressão deriva do substantivo inglês gentry, que designa indivíduos ou grupos "bem nascidos", de "origem nobre". Assim, foi concebida originalmente para fazer referência a um processo de elitização ou de "enobrecimento" de determinados lugares da cidade, anteriormente caracterizados como áreas predominantemente populares. Nos anos 1980, o debate sobre a gentrificação tornou-se um assunto de grande repercussão no meio acadêmico, especialmente nos países de língua inglesa. Diante da expressiva proliferação de experiências com características semelhantes ao processo identificado por Glass, o debate acerca da gentrificação deixou de ser um tema restrito ao meio acadêmico no contexto atual, tornando-se uma questão razoavelmente conhecida e discutida mesmo entre não especialistas.

Pensar sobre a atualidade desse conceito e sua possível contribuição para compreender e explicar a produção do espaço urbano nos dias de hoje traz alguns desafios. 0 primeiro deles é delimitar o que se entende por gentrificação, termo que chegou a ser qualificado como um "conceito caótico" em virtude da pluralidade de sentidos com que veio a ser empregado (Zukin, 1987, p. 132). 0 uso indiscriminado desse termo para fazer referência a qualquer experiência de transformação do espaço urbano de caráter socialmente excludente - embora possa fazer sentido como estratégia argumentativa - acaba por ofuscar suas especificidades, provocando seu esvaziamento como categoria de análise. A banalização de seu emprego em discursos críticos sobre as transformações observadas na cidade contemporânea dificulta a formulação de hipóteses acerca da dimensão e do papel dos processos de gentrificação e de suas conexões com tendências mais abrangentes que afetam o modo de produção capitalista em sua fase atual.

No intuito de contribuir para o aprofundamento das reflexões teóricas sobre a gentrificação, este artigo buscará trazer aportes que favoreçam a delimitação dos contornos desse conceito. Partiremos de sua acepção mais específica, em que o termo é empregado como sinônimo de um processo que tem como traços fundamentais a retomada de investimentos em centros urbanos que passaram por períodos prolongados de decadência 
e a alteração do perfil socioeconômico desses lugares. Em seguida, buscaremos evidenciar algumas dificuldades metodológicas provocadas pela extrapolação desse sentido mais restrito do conceito.

Após uma discussão inicial a respeito da dimensão territorial dos processos de gentrificação, o artigo passará a tratar do debate sobre suas forças motrizes. Tal reflexão será feita buscando-se identificar os argumentos centrais apresentados em algumas das principais abordagens teóricas referentes ao tema, expondo-se os pontos de divergência e eventuais pontos de contato entre elas. Mais do que simplesmente mapear o debate, descrevendo e classificando diferentes correntes de pensamento, o intuito é apontar os limites dos modelos explicativos existentes e identificar possíveis pontos de complementaridade entre argumentos aparentemente contrapostos.

Argumentaremos que os modelos explicativos centrados em fatores como a mudança de padrões culturais e a escolha do consumidor, inspiradas sobretudo nos trabaIhos de David Ley, podem ser articulados com explicações elaboradas a partir da hipótese do diferencial de renda (rent gap), baseadas principalmente nas formulações teóricas de Neil Smith. Nessa tentativa de aproximação entre as perspectivas teóricas centradas na oferta e aquelas centradas na demanda, apontaremos a atribuição de conteúdo econômico a elementos simbólicos presentes em determinados fragmentos urbanos como fundamento da ativação de rendas potenciais latentes. Argumentaremos que os centros históricos apresentam possibilidades de valorização diferenciadas em virtude de fatores que transcendem as oportunidades de reinvestimento decorrentes dos ciclos de realização e depreciação dos capitais incorporados ao espaço urbano.

Explorando as conexões entre os "argumentos locais" e os "argumentos globais" de Neil Smith (1996) com apoio em algumas formulações de David Harvey (1989), apresentaremos uma leitura da gentrificação como fenômeno que sintetiza diversos aspectos de um regime de acumulação centrado na racionalidade financeira, fundamentando-se em processos espoliativos, no encurtamento do tempo de giro do capital e na focalização territorial das intervenções urbanas. A construção desse raciocínio se valerá dos apontamentos feitos anteriormente quanto à dimensão territorial e às forças propulsoras dos processos de gentrificação, buscando relacionar o que se entende como momentos articulados de transformações que perpassam várias escalas geográficas.

\section{A dimensão territorial da gentrificação}

Em busca da formulação de uma teoria capaz de explicar a difusão dos processos de gentrificação, Neil Smith propõe uma definição preliminar desse fenômeno como uma entrada de capitais privados e de moradores de classe média e alta em bairros populares localizados em antigos centros urbanos que passaram por períodos prolongados de carência de investimentos. ${ }^{1}$ Esse movimento do capital seria guiado fundamentalmente pelo que o autor chama de diferencial de renda. ${ }^{2}$

Após o transcurso de um lapso de tempo razoavelmente longo em que tais localidades permanecem de fora dos focos prioritários 
de investimento no espaço construído, então direcionados preferencialmente às frentes de expansão suburbana, a renda auferida com a exploração econômica dos imóveis localizados na área central se reduz até o momento em que a diferença entre a renda potencial e a renda efetivamente capitalizada com os atuais usos da terra ultrapassa um patamar crítico. Alcançado esse estágio, os possíveis acréscimos de renda com o reinvestimento no antigo centro passam a suplantar aqueles que poderiam ser obtidos com a abertura de novas frentes de urbanização nas franjas periféricas. Configurado esse cenário, a direção dos fluxos de capital se inverte, e o antigo centro desponta como nova "fronteira". Junto com os investimentos, essas localidades passam a receber um público por quem haviam sido abandonadas em virtude de sua alegada degradação. 0 retorno do capital e dos segmentos sociais de maior poder aquisitivo ao centro, por sua vez, resulta numa paulatina substituição de seus antigos moradores e frequentadores, que dificilmente conseguem resistir à pressão decorrente das mudanças a que essas localidades são submetidas no bojo de seu enobrecimento (Smith, 1996).

Mais do que a expressão de uma repentina mudança cultural, ou de uma súbita inversão de preferências entre a vida no subúrbio e a vida na cidade, para Smith, a volta ao centro se explica fundamentalmente por fatores objetivos relacionados à economia política do processo de urbanização, sinalizando uma inversão nos potenciais acréscimos de renda passíveis de serem obtidos com a realização de investimentos nos vetores de expansão suburbana e aqueles encontrados na área central.

Na perspectiva de Smith (1996), entretanto, a gentrificação não pode ser encarada apenas como um produto automático da dinâmica do mercado imobiliário, contendo uma dimensão política e pressupondo o emprego de dispositivos ideológicos. Convertidos em redutos populares após anos de carência de investimentos, a retomada dos antigos centros como plataformas "estratégicas" de valorização do capital mostra-se um processo inevitavelmente conflituoso. Tais estratégias envolvem a formação de coalizões entre agentes privados e o Estado, o uso de meios de coerção econômica ou extraeconômica e a mobilização de um engenhoso arsenal ideológico-discursivo para minar possíveis resistências, constituindo o cenário que Smith caracteriza como uma "cidade revanchista".

Embora haja um grau razoável de acordo no debate quanto ao caráter classista do processo de gentrificação e quanto ao crescimento progressivo de sua importância, uma série de objeções foram feitas às tentativas de explicá-lo a partir do argumento do diferencial de renda, perspectiva que tem em Smith seu principal representante (Slater, 2011, p. 575). Tais críticas questionaram tanto o modo como a dimensão territorial da gentrificação é tratada por Smith, quanto os fatores que o autor identifica como forças motrizes do processo. Em relação ao primeiro aspecto, alguns dos opositores de Smith alegam que seu modelo explicativo não permitiria que se previssem quais os lugares onde as condições para a deflagração do processo de gentrificação estariam presentes, por onde ele se iniciaria, nem o ritmo e a intensidade com que poderia ocorrer em diferentes localidades, de modo que a hipótese do diferencial de renda não passaria de uma proposição teórica excessivamente abstrata, com pouca 
operacionalidade prática e de respaldo empírico duvidoso (Ley, 1987, p. 466).

Buscando submeter a hipótese do diferencial de renda à prova, David Ley conduziu pesquisas empíricas nas principais cidades canadenses, desenvolvendo uma metodologia para verificar, entre outras questões, se os lugares onde o processo de gentrificação vinha ocorrendo tinham ou não seguido a trajetória prevista no modelo explicativo de Smith. Os resultados das pesquisas de Ley levaram o autor a questionar a própria suposição de que o diferencial de renda fosse efetivamente um indutor do processo de gentrificação, uma vez que não teriam sido observadas correlações entre uma coisa e outra. 0 autor fundamenta seu raciocínio na alegação de que se constatou a ocorrência de gentrificação num ritmo mais intenso justamente em cidades onde a relação entre o preço de residências na área central e aqueles verificados no restante das respectivas regiões metropolitanas eram as mais elevadas, o que constituiria uma evidência contrária à tese de Smith. ${ }^{3}$

Questionando a metodologia da pesquisa de Ley, Eric Clark alega que seu esforço não logrou efetivamente submeter a hipótese de Smith a um teste empírico, uma vez que, em decorrência de um entendimento equivocado da noção de diferencial de renda, Ley teria analisado o comportamento de variáveis que não serviriam para comprová-la ou refutá-la (Clark, 1988, p. 2450). Segundo Clark, no referido estudo, Ley confunde duas grandezas de natureza distinta, a diferença entre o preço dos imóveis na área central e o preço dos imóveis no restante da cidade e a diferença entre a renda potencial e a renda efetiva num mesmo lugar, tomando a primeira relação, ao invés da segunda, como expressão do diferencial de renda. Esse equívoco teria levado o autor a conclusões infundadas quanto à inexistência de correlações mensuráveis entre diferencial de renda e gentrificação. ${ }^{4}$ Insatisfeito com o teste realizado por Ley, Clark submeteu a hipótese do diferencial de renda a uma nova verificação empírica, desta vez a partir de estudos de caso conduzidos na cidade de Malmö, na Suécia. As tendências observadas em seus estudos, ao contrário da pesquisa de Ley, trouxeram evidências em favor da hipótese de Smith, mostrando a existência de correlação positiva entre diferencial de renda e gentrificação (Clark, 1988).

$\mathrm{Na}$ esteira das críticas à perspectiva de Smith, Sharon Zukin aponta outras lacunas em seu modelo teórico. Embora reconheça que a noção de diferencial de renda represente um aporte útil para se refletir sobre a dinâmica territorial dos investimentos nas cidades, e que o fenômeno por ela expresso constitua efetivamente uma condição propícia para a ocorrência de processos de gentrificação, a autora relativiza seu poder explicativo, afirmando tratar-se de um argumento "mecanicista e, de certa forma, circular", em que todos os outros fatores são tratados como questões secundárias de pouca relevância (Zukin, 1987, p. 137). Para a autora, a exacerbação de sua importância fez com que se considerasse o referido processo uma decorrência automática da diferença entre a renda potencial e a renda efetiva. Entretanto, sujeita a outras causalidades, a gentrificação nem sempre se concretizaria em todos os lugares onde tais condições estivessem presentes, e nem sempre seguiria uma cronologia correspondente às diferentes magnitudes da relação entre a renda capitalizada e a renda potencial, aspectos que aponta como limites para pensar 
a dinâmica territorial desse processo com base na perspectiva de Smith.

0 autor rebate as objeções de que 0 argumento do diferencial de renda ofusca as especificidades das experiências concretas e de que não permite predizer quais serão os próximos focos do processo de gentrificação questionando a relevância dessas indagações. Em suas palavras, mais relevante do que olhar para tais processos perguntando-se "quem", "quando" e "onde", a principal pergunta a ser feita deveria ser "por que" (Smith, 1982, p. 139). Enquanto autores como Ley (1986), Lipton (1977), Butler S. (1986), Laska e Spain (1980) e outros estariam preocupados prioritariamente em descrever particularidades de casos específicos, Smith afirma ter como principal propósito tratar o tema da gentrificação a partir de uma perspectiva teórica, concentrando-se na procura de suas causas. Assim, é esperado que sua abordagem apresente um nível de abstração mais elevado do que aquele que seus críticos achariam desejável, e que ela não dê conta de responder satisfatoriamente todas as suas indagações. No entanto, se algumas dessas preocupações extrapolam 0 escopo de sua análise, cabe ressalvar que a indeterminação da abrangência territorial do processo de gentrificação impõe algumas dificuldades internas ao próprio modelo teórico formulado por Smith, o que constitui uma objeção mais incômoda.

A caracterização introdutória proposta pelo autor, aqui bastante simplificada, oferece uma imagem razoavelmente clara da dinâmica espacial dos processos de gentrificação em seu início. Ela transmite a ideia de um processo cíclico de alternância das ofensivas do capital entre o centro mais antigo e os vetores de expansão suburbana, uma espécie de sístole e diástole do capital impulsionadas por fases sucessivas de ampliação, realização e esgotamento do potencial de valorização em diferentes fragmentos do tecido urbano. A aparente nitidez do cenário caracterizado nesse modelo teórico começa a se desfazer quando o autor afirma que a gentrificação teria extrapolado os limites do que se reconhece como centro urbano. A pretensão de explicar os processos de gentrificação a partir da hipótese do diferencial de renda passa a enfrentar maiores dificuldades no momento em que Smith alega que tal processo passou da condição de "anomalia local" à de "estratégia global", tornando-se um fenômeno generalizado. ${ }^{5}$

Em várias de suas obras dedicadas ao tema, Smith esboça uma periodização da evolução histórica da gentrificação (Smith, 2002, pp. 437-446; 2006, pp. 59-87). Em seus primórdios, o processo estaria restrito aos centros antigos de um conjunto reduzido de cidades do capitalismo avançado, notadamente as principais metrópoles do mundo anglo-saxônico, como Londres, Nova York, Toronto e Sidney, e algumas outras capitais de destacada importância econômica, como Paris e Tóquio. Nesse período, compreendido entre os anos 1960 e meados da década de 1970, a gentrificação não passaria de uma espécie de "esporte urbano" praticado por uma elite excêntrica, um fenômeno esporádico de escala e alcance territorial limitados, não indo além do setor residencial e dos centros históricos dessas cidades. Essa primeira fase do processo abrangeria fundamentalmente experiências do tipo das que foram relatadas no estudo de Ruth Glass (1964), em que se empregou o termo "gentrificação" pela primeira vez. 
A partir do final da década de 1970, teria se iniciado uma segunda fase. Nesse período, o processo passaria a se manifestar num universo geográfico mais amplo. Além disso, teria se transformado num fenômeno muito mais abrangente nos lugares onde vinha ocorrendo há mais tempo, extrapolando o centro antigo e indo além do setor residencial. Nessa fase, a gentrificação teria se propagado em sentido horizontal e vertical nas principais cidades do capitalismo avançado, e também atingido novas cidades.

A terceira e última fase é aquela em que, segundo o autor, a gentrificação tonou-se um fenômeno generalizado, difundindo-se por boa parte do mundo e alcançando proporções sistêmicas em diversas cidades. Essa etapa teria se iniciado em meados dos anos 1990, tendo como pano de fundo uma agenda urbana concebida num contexto de hegemonia do modelo neoliberal. Nessa fase, ainda que em estágio inicial, os processos de gentrificação teriam alcançado cidades da América Latina, como São Paulo (Smith, 1996, p. 36).

Nas formulações teóricas de Smith, a gentrificação não é tomada como simples reflexo de uma determinada conjuntura econômica, mas como um de seus momentos constitutivos, figurando simultaneamente como causa e efeito da primeira. Na perspectiva do autor, a ofensiva desse processo sobre os bairros populares nos centros urbanos integra uma estratégia de reprodução do capital e do poder de classe, agindo no sentido de aprofundar um padrão de desenvolvimento desigual na escala intraurbana (Smith, 2002). A difusão da gentrificação, nesse sentido, encontra-se em sintonia com a ampliação das desigualdades sociais observada ao longo das últimas décadas. Se a extensiva suburbanização do período pós-guerra representou um momento de preponderância das forças de equalização do desenvolvimento territorial, inscrevendo no espaço um processo de ampliação das condições materiais de reprodução social, a difusão da gentrificação, por sua vez, expressaria uma guinada no sentido oposto, em que as forças que impulsionam a diferenciação e o desenvolvimento desigual tornaram-se preponderantes (Smith, 1982, pp. 142-145). Para o autor, a "volta ao centro" constitui um movimento de concentração do capital que se expressa espacialmente sob a forma de uma intensificação do padrão desigual do desenvolvimento geográfico na escala intraurbana, e cujo sentido mais profundo é o aumento das disparidades socioeconômicas. ${ }^{6}$ Pensar a gentrificação a partir desse referencial teórico oferece uma base conceitual que permite enxergar as transformações espaciais como processos articulados a transformações sociais mais abrangentes, o que constitui uma preocupação central de Smith. Entretanto, ao dimensionar a gentrificação em seu estágio atual como um fenômeno generalizado, a conexão que havia sido evidenciada entre seu sentido socioeconômico e sua expressão espacial perde aderência.

0 caráter espacialmente indefinido atribuído pelo autor ao fenômeno da gentrificação em sua última fase impõe algumas dificuldades para pensá-la com base na hipótese do diferencial de renda e no movimento de retorno do capital ao centro. Como conciliar um entendimento da gentrificação como reorientação dos fluxos de capital dos subúrbios em direção aos centros urbanos com a alegação de que o referido processo transformou-se num fenômeno generalizado? Em outras 
palavras, até que ponto é possível tratar os focos de enobrecimento dispersos pelo tecido urbano como evidências de uma "gentrificação generalizada" sem que, ao mesmo tempo, não se desconstrua implicitamente 0 argumento da diferencial de renda - supostamente a força motriz do processo de gentrificação?

Esses questionamentos não dizem respeito apenas a aspectos de ordem morfológica, mas aos próprios fundamentos sociais do processo em questão. Se a gentrificação consiste na retomada de bairros populares por classes de maior poder econômico - que constituem segmentos sociais numericamente inferiores - há uma impossibilidade de que tal fenômeno se generalize pelo território. Ainda que seus focos se dispersem - o que já impõe um desafio à defesa da hipótese do diferencial de renda - trata-se de um fenômeno necessariamente circunscrito a porções limitadas do tecido urbano. Caso contrário, expressaria uma intensificação das forças de equalização do desenvolvimento territorial, justamente 0 contrário do que Smith supõe como sentido social subjacente à gentrificação - a escalada das forças de diferenciação.

Seria precipitado dizer que Smith não vislumbrou tais objeções, e que não ofereça qualquer tipo de resposta a elas (ver Smith, 1996, p. 37). Em primeiro lugar, o autor não trata o centro urbano como uma realidade estática. Ao contrário, chama a atenção para a ocorrência de uma abrangente redefinição das escalas geográficas e da interação entre elas como fatores centrais para se compreender a dinâmica das cidades no mundo contemporâneo. Em sua concepção, os limites do que se entende como centro de uma cidade não são perímetros fixos e imutáveis, passíveis de demarcação cartográfica. 0 centro não é uma circunscrição territorial definida, mas uma representação do espaço que expressa identidades socialmente construídas a partir da identificação de relações de hierarquia entre diferentes fragmentos urbanos. Trata-se de uma abstração cuja expressão territorial se redefine permanentemente, sendo influenciada por interações entre processos que operam em diferentes escalas geográficas.

Por um lado, a indeterminação dos limites do centro urbano subjacente à hipótese da gentrificação generalizada abre espaço para se pensar as configurações socioespaciais na cidade sem que se caia numa perspectiva formalista. Nesse sentido, é plausível supor que, ao caracterizar a gentrificação como um fenômeno generalizado, Smith não tenha julgado tratar-se de um processo que atinja o tecido urbano em sua totalidade, nem de uma onda que se propague aleatoriamente, mas sim de uma prática que não está confinada aos centros tradicionais, manifestando-se num universo territorial mais abrangente e redefinindo ao longo de seu próprio curso a escala daquilo que é tido como centro urbano. A metáfora da "fronteira urbana" reforça esse entendimento.

No entanto, embora seja possível deduzir essa interpretação, a ausência de maiores esclarecimentos por parte de Smith quanto à relação entre o caráter generalizado do processo de gentrificação e a mudança de escala da centralidade urbana acaba por favorecer a atribuição de um sentido caótico a esse conceito, dando margem para que seu uso seja estendido de modo a abarcar também processos de suburbanização. 0 tratamento indiferenciado desses dois processos opostos é algo que atinge uma das principais preocupações 
metodológicas de Smith, que é pensar a gentrificação numa chave teórica que permita a identificação de conexões entre o metabolismo do capital e a forma urbana.

A indeterminação territorial não é o único ponto de fragilidade do modelo explicativo centrado no diferencial de renda. Outra limitação interna dessa perspectiva analítica é a identificação das causas que condicionam a variação da renda potencial de uma determinada localidade. A carência de teorização sobre os fatores determinantes da renda potencial abre margem para a crítica feita por Zukin acerca do caráter circular do argumento do diferencial de renda. Acredita-se aqui que as teorias centradas na demanda oferecem elementos explicativos capazes de contribuir, em alguma medida, para a superação dessa dificuldade. Mais do que isso, ao possibilitar que se vislumbrem com maior nitidez os possíveis campos de incidência dos processos de gentrificação, o esforço de articulação dessas duas matrizes teóricas pode contribuir para reforçar a leitura do impulso desse fenômeno como expressão espacial de um regime específico de acumulação do capital.

\section{As forças motrizes da gentrificação}

A produção literária sobre o tema da gentrificação polarizou-se em torno de duas correntes de pensamento nos anos 1980, que ficaram associadas às figuras de Smith e Ley. Tom Slater sintetiza a dicotomia que se instaurou no debate como uma divergência decorrente dos diferentes pesos atribuídos a fatores como produção e consumo, oferta e demanda, estrutura e comportamento individual (Slater, 2011, p. 575). Smith, tributário da tradição materialista, tornou-se o principal expoente de uma perspectiva centrada na produção e na oferta, enquanto Ley, partindo de um referencial teórico mais focado no papel do indivíduo, estabeleceu-se como o principal representante da outra perspectiva, centrada no consumo e na demanda.

Ambas as correntes tiveram como ponto em comum o fato de terem se originado de uma insatisfação com os modelos explicativos formulados a partir do referencial teórico da economia urbana de matriz neoclássica (Zukin, 1987). Essas abordagens explicavam a gentrificação como um ajuste do mercado às oscilações de preço dos imóveis, encarando-a como um processo racional e, em geral, conferindo-Ihe uma conotação positiva. ${ }^{7}$ A busca de alternativas à perspectiva neoclássica levou ao surgimento das duas correntes mencionadas, que fizeram com que o tema da gentrificação se tornasse uma fonte de acalorados debates acadêmicos.

De um lado, as teorias centradas na demanda buscaram explicar a difusão desse processo fundamentalmente a partir de fatores culturais, e de sua influência sobre os padrões de consumo de produtos imobiliários. A gentrificação teria como principal força motriz uma insatisfação com o marasmo da vida nos subúrbios e uma guinada na preferência de alguns segmentos sociais em favor da vida nos centros urbanos. A identificação do perfil dos gentrificadores despontou como uma questão central nessas análises, sendo frequente a caracterização de certos grupos como protagonistas do processo. Como exemplos, são mencionados de 
modo recorrente os jovens profissionais ligados aos serviços urbanos, os artistas, os trabalhadores com alto nível de formação educacional, entre outros (Ley, 2003). Também aparecem com frequência argumentos subsidiários centrados em fatores de ordem demográfica, em questões de gênero, nas chamadas economias de aglomeração, bem como nos impactos urbanos decorrentes da reestruturação produtiva do final do século XX. Nesse sentido, são apontados fatores como o alcance da idade adulta pela geração do baby boom e a saída em massa desses jovens da casa de suas famílias; a emancipação das mulheres e sua entrada no mercado de trabalho; o surgimento de novas formas de convivência alternativas às famílias convencionais; a opção pela vida no centro como alternativa aos altos custos de transporte, especialmente após os choques do petróleo; a reestruturação produtiva e a transição para uma economia de serviços, marcada pela redução da oferta de empregos na indústria e sua ampliação nas atividades terciárias, localizadas majoritariamente nos centros urbanos; o surgimento de uma nova classe média ligada aos serviços urbanos; entre outros (Ley, 1980). Todos esses argumentos foram mobilizados nessas abordagens para fundamentar a explicação dos processos de gentrificação como uma decorrência da elevação da procura pelos centros urbanos.

No outro polo do debate, os modelos teóricos centrados na oferta buscaram explicar o processo de gentrificação a partir da hipótese da inversão das perspectivas de rentabilidade de investimentos associados à produção do espaço urbano no centro e nas frentes de expansão suburbana, sintetizando-o como um movimento de volta à cidade impulsionado não pelas pessoas, mas fundamentalmente pelo capital. ${ }^{8}$ As transformações econômicas do final do século XX também são identificadas como um aspecto relevante para se pensar a gentrificação, mas em outro sentido. Enquanto Ley (1980) projeta a imagem de uma "cidade pós-industrial" com um ascendente setor de serviços e novos modos de vida impulsionando 0 aquecimento do setor imobiliário nos centros, Smith (2006) e outros autores mais alinhados às teorias centradas na oferta, como Harvey (1989), entendem que as conexões entre a gentrificação e a expansão das finanças se dão fundamentalmente pelo escoamento de massas de capital para os centros num contexto em que a produção do espaço urbano é mobilizada como negócio de importância ascendente. ${ }^{9}$

Embora os representantes dessas duas correntes tenham se confrontado em diversas oportunidades, dedicando-se com afinco a expor as inconsistências teóricas do lado oposto e reunindo evidências empíricas favoráveis à comprovação de suas próprias hipóteses, também não faltaram iniciativas no sentido de relativizar suas divergências e admitir a importância do diálogo recíproco. Os dois lados reconheceram a existência de limitações em seus respectivos argumentos e a pertinência de algumas das proposições da corrente oposta, destacando a importância de se buscar uma superação da clivagem a que se chegou. No entanto, a disposição em se abrir para a outra perspectiva nem sempre resultou em sínteses efetivas. Segundo o próprio Smith, de modo geral, as tentativas de intercruzamento dos dois referenciais analíticos não lograram ir além de pequenas concessões seguidas pela reafirmação do maior poder explicativo do próprio campo, sem que se tenha rompido com 
a cisão estabelecida no debate sobre o tema (Smith, 1996). Diante desse alerta, é importante ter em mente que a busca por pontos de complementaridade entre essas duas perspectivas não é uma proposta original, nem uma tarefa simples, oferecendo riscos consideráveis de redundar num esforço pouco frutífero. Ainda assim, entende-se aqui que, com algumas precauções, essa tentativa pode contribuir para o avanço do debate.

A hipótese do diferencial de renda parece ser de fato o aporte teórico que mais contribui para que se avance na reflexão acerca das causas comuns aos diferentes processos de gentrificação, bem como para entender as razões que fazem com que ele se manifeste num conjunto de lugares tão amplo e diversificado. No entanto, algumas das críticas formuladas em relação aos limites do poder explicativo desse argumento não permitem concluir que se tenha alcançado uma base conceitual satisfatória e definitiva para explicar a gentrificação.

Ao alertar para seu caráter circular, Zukin detectou o que poderia ser chamado de calcanhar de Aquiles das perspectivas analíticas formuladas a partir da noção do diferencial de renda. 0 fato de ter se constituído previamente um diferencial de renda nos lugares que passaram ou que estão passando por processos de gentrificação é um argumento dificilmente refutável. No entanto, ele só permite que se detecte essa condição a posteriori, quando o fenômeno já está em marcha, não oferecendo nenhum elemento de análise que explique as razões do descolamento entre a renda capitalizada e a renda potencial. A gentrificação ocorre em função do diferencial de renda, mas o que dá origem a ele? A pergunta poderia ser redirecionada para o ponto cego do argumento do diferencial de renda: quais são os fatores que provocam a elevação da renda potencial num determinado fragmento urbano?

Em suas reflexões mais recentes, Ley traz elementos que podem ajudar a responder essa pergunta. Num artigo intitulado "Artistas, estetização e o campo da gentrificação" (Ley, 2003), o autor apresenta hipóteses que contribuem para a reflexão acerca dos fatores que determinam os potenciais de valorização presentes em algumas áreas da cidade, especialmente nos centros urbanos tidos como degradados. Ley identifica uma dinâmica em que, pela ação de artistas e outros agentes com hábitos culturais tidos como excêntricos, o caráter marginal de certas áreas da cidade é ressignificado, de modo que o que era sinônimo de degradação e abandono converte-se num atributo estético apreciado. ${ }^{10}$ Fatores como a disponibilidade de um patrimônio arquitetônico singular, a diversidade social, a presença de uma atmosfera cultural underground e os preços imobiliários depreciados constituem-se como importantes atrativos para esses agentes, que passam a ocupá-las e a induzir sua transformação. Com o avanço do processo de "reciclagem" dessas áreas, inicialmente impulsionado pela ação criativa dos artistas, elas passam a atrair públicos de outro perfil, com poder aquisitivo mais elevado, ainda que a contragosto daqueles que deram início a sua transformação. Nesse momento, a atmosfera de decadência e marginalidade, cada vez mais imaginária do que real, passa a figurar como diferencial estético, sendo mensurada economicamente e incorporando-se ao valor de produtos imobiliários até então depreciados. ${ }^{11}$ 
Apoiando-se em conceitos formulados originalmente por Pierre Bourdieu (1984), Ley sustenta que alguns grupos economicamente marginais exerceriam um papel relevante na formação dos padrões estéticos dos setores dominantes. Esse seria o fundamento da atribuição de valor econômico à efervescência cultural e ao ambiente despojado de alguns centros urbanos e de outras áreas tidas como degradadas que se transformaram em redutos de artistas e outros segmentos sociais "ricos em capital simbólico mas pobres em capital econômico". ${ }^{12}$ As áreas onde se observa essa defasagem entre 0 que o autor chama de capital simbólico e o capital econômico constituiriam os campos propícios à ocorrência de processos de gentrificação.

A incorporação desse aporte teórico às abordagens centradas na oferta permite conceber a renda potencial em termos menos vagos, contribuindo para que se superem algumas das limitações explicativas do argumento do diferencial de renda. $A$ incorporação do argumento da diferença entre o capital simbólico e o capital econômico à hipótese do diferencial de renda permite pensá-la não apenas em função da deterioração do capital fixo e da expansão do tecido urbano, mas como efeito de uma combinação entre a dinâmica dos ciclos de investimento e a presença de atributos estéticos singulares em locais específicos. A partir dessa perspectiva, torna-se possível conceber quais seriam os possíveis campos de incidência dos processos de gentrificação de modo menos aberto, o que abre caminhos para que se avance numa das principais preocupações metodológicas subjacentes às teorias centradas na oferta, que é identificar nexos entre as mudanças observadas na escala das cidades e transformações sociais mais abrangentes.
Harvey, embora partindo de premissas metodológicas distintas das de Ley, levanta hipóteses em alguma medida semelhantes às suas no que se refere às mudanças culturais e à atribuição de conteúdo econômico à estética das cidades. No entanto, o autor aborda esses fatores de modo articulado com reflexões sobre os movimentos do capital e a economia política da urbanização. 0 autor aponta como um traço característico do urbanismo contemporâneo o fenômeno a que chama de espetacularização, que o diferenciaria substancialmente do urbanismo moderno, marcado pela rigidez e sobriedade das formas e pela preponderância de uma racionalidade funcionalista. Essa mudança observada no âmbito do urbanismo seria um componente de transformações mais abrangentes vivenciadas no capitalismo contemporâneo, sintetizadas nas formulações desse autor como uma transição de um regime de acumulação fordista para um regime de acumulação flexível (ver Harvey, 1992, pp. 163-176). Pode-se dizer que, em sua obra, a noção de regime de acumulação flexível representa um esforço de teorização ainda inacabado sobre as mudanças no metabolismo do capital diante da crise do regime de acumulação anterior, marcado pelo papel preponderante da indústria como fator dinâmico do desenvolvimento econômico. A emergência do atual regime de acumulação teria como um de seus elementos constitutivos a adoção de uma estratégia abrangente voltada para a abertura de frentes para a ação do capital, o que englobaria a criação de novos campos de produção e realização de valor, a comoditização de bens e atividades até então não completamente incorporados à esfera mercantil, a propagação de novas necessidades de consumo e, de modo geral, a aceleração do 
tempo de giro do capital através da difusão de mercadorias de produção e consumo fugazes. $A$ arte, a cultura e a indústria do entretenimento figurariam como campos privilegiados desse processo de ampliação da esfera de produção e realização de valor. ${ }^{13}$

As cidades de modo geral e especialmente os antigos centros urbanos seriam impactados por essa nova conjuntura econômica de diversas maneiras. Além de se tornarem importantes escoadouros de capitais produtivos e rentistas empregados no desenvolvimento imobiliário, eles figurariam como incubadores de novas mercadorias, necessidades de consumo e estilos de vida num regime de acumulação não mais capitaneado pela atividade industrial, mas pela produção de bens simbólicos (Harvey, 1989, p. 11). Mais do que isso, constituiriam uma matéria-prima particularmente versátil para a ação do capital num contexto em que a produção de imagens espetaculares tornou-se um dispositivo fundamental de sua reprodução. Congregando um conjunto diversificado de grupos sociais, expressões culturais, formas arquitetônicas raras, entre outros atributos que os distinguem da homogeneidade monótona que prevalece no restante da cidade, os centros ofereceriam um potencial não encontrável em qualquer fragmento urbano para a funcionalização de atributos estéticos e a produção de paisagens de caráter espetacular.

Para Harvey, certas mudanças nos paradigmas de gestão urbana associadas à transição para o regime de acumulação flexível também constituem fatores-chave para compreender as transformações que atingem os centros das cidades nos dias de hoje. Segundo o autor, um dos desdobramentos da emergência do regime de acumulação flexível foi a passagem do que chama de "administrativismo" para o "empreendedorismo". ${ }^{14}$ Além de uma significativa mudança no papel do Estado, esse novo paradigma teria como um de seus desdobramentos fundamentais a passagem de uma racionalidade centrada em planos para outra centrada em projetos. No lugar dos planos modernistas, em que a cidade figurava como objeto de planificação em sua totalidade, a gestão urbana passou a se orientar para a promoção de projetos em locais específicos, substituindo-se uma concepção universalista por um padrão focalizado de intervenção no território. 0 caráter utópico dos antigos planos foi abandonado em favor do pragmatismo de ações localizadas, com custos e tempos de realização mensuráveis, e mais condizentes com uma racionalidade empresarial. As políticas abrangentes de desenvolvimento territorial de longo prazo características do período anterior - estreitamente relacionadas à inversão de capital nas frentes de expansão suburbana perderam força, e os investimentos passaram a se concentrar em projetos urbanos capazes de oferecer altas taxas de retorno em curto espaço de tempo. A remodelação de centros urbanos ditos decadentes despontou, então, como uma modalidade de intervenção recorrente, 0 que impulsionou a difusão dos processos de gentrificação por diversas cidades do mundo, contribuindo para intensificar as desigualdades socioespaciais. ${ }^{15}$

Harvey associa a ascensão do empreendedorismo urbano e, de modo mais amplo, a racionalidade subjacente ao regime de acumulação flexível, à supremacia alcançada pelo capital financeiro na atual conjuntura. Para 0 autor, a preponderância da lógica das finanças como fator de coordenação dos processos 
econômicos no período de hegemonia do pensamento neoliberal é o fundamento de diversas das transformações identificadas no período, dando causa a fenômenos como o encurtamento do horizonte temporal do planejamento, a redução de escala e a focalização das intervenções no espaço urbano, a afirmação do pragmatismo empresarial como paradigma de gestão e a crescente estetização do processo produtivo. Esses fatores se articulam numa estratégia abrangente orientada para a abertura de novas esferas de acumulação e para a redução do tempo de giro do capital (Harvey, 1989). Para o autor, eles também estão relacionados a outro aspecto emblemático do atual estágio do capitalismo, que é a dominância do que chama de acumulação por espoliação (Harvey, 2003).

Essa noção é central para se entender os sentidos que Harvey atribui à emergência do regime de acumulação flexível e seus desdobramentos nas cidades. Essa expressão é uma releitura do conceito de acumulação primitiva de Marx. ${ }^{16} 0$ debate acerca da longevidade do processo de acumulação primitiva e a aplicabilidade desse conceito aos dias de hoje é um tema controverso. Discute-se se ele caracterizaria um momento histórico na trajetória do desenvolvimento capitalista, completado no passado ou em vias de se completar, ainda que em ritmos diferenciados conforme o contexto geográfico, ou se representaria um momento lógico desse modo de produção, manifestando-se sob novas formas mesmo em seu estágio avançado. Alinhando-se à segunda hipótese, ${ }^{17}$ Harvey entende haver uma coexistência de tendências contrapostas ao longo da trajetória do capitalismo, a reprodução ampliada do capital e a acumulação por espoliação. A reprodução ampliada teria como fundamento a expansão da base material sobre a qual se dá o metabolismo do capital e a reprodução social, enquanto a acumulação por espoliação estaria baseada na incorporação à esfera da circulação capitalista de bens e recursos inicialmente produzidos e apropriados em regimes comunais, o que ocorreria por meio da imposição de direitos de propriedade sobre eles. 0 desenvolvimentismo de inspiração keynesiana do período pós-guerra ilustraria de modo emblemático um contexto de predominância da reprodução ampliada, enquanto a atual conjuntura econômica, marcada pela supremacia do pensamento neoliberal e da racionalidade intrínseca ao capital financeiro, expressaria uma guinada em direção à acumulação por espoliação (Harvey, 2003, pp. 78-79).

A mudança nos paradigmas de planejamento e gestão urbana seria um dos desdobramentos dessa inversão. De modo bastante semelhante à leitura que Smith faz do urbanismo neoliberal, Harvey preconiza que, ao invés de forjar um espaço adequado à reprodução ampliada de sua base material por meio da implementação de planos de desenvolvimento territorial de longo prazo e de perspectiva universalista, num regime marcado pela predominância da acumulação por espoliação, as estratégias do capital passaram a ser orientadas para a captura sistemática de oportunidades de negócio de alta rentabilidade e retorno rápido, o que, entre outros efeitos, deu impulso aos processos de gentrificação (Harvey, 2008, p. 34). Para o autor, esse movimento do capital, intermediado pelo aprofundamento das conexões entre a esfera financeira e a propriedade urbana, faz com que as áreas onde se constatem diferenciais de renda em patamares elevados convertam-se em alvos prioritários, sendo 
tomadas de assalto pelo capital com base numa combinação de dispositivos de violência de natureza econômica e extraeconômica (Harvey, 2003). 0 objeto da ação especulativa nas cidades - permeada por processos de espoliação - não diz respeito apenas à propriedade fundiária e ao espaço edificado, mas também à sua dimensão simbólica, que constitui um dos fundamentos da valorização dos primeiros, de modo que sua funcionalização econômica tornou-se um fator-chave do atual regime de acumulação (Harvey, 1992).

Os aportes teóricos trazidos por Harvey, assim como os de Ley, ajudam a refletir sobre os processos de gentrificação ao associarem as possibilidades de valorização a fatores que vão além dos ciclos de realização e depreciação dos capitais incorporados ao espaço urbano e da ampliação da escala das cidades. Suas abordagens oferecem instrumentos analíticos que ajudam a identificar situações de defasagem entre a renda capitalizada e a renda potencial, e também a entender por que os centros - e não qualquer lugar da cidade - são áreas especialmente propensas a passar por um processo desse tipo. Ambos levam em conta fatores relacionados às mudanças nos padrões culturais e seus impactos sobre a demanda e os hábitos de consumo, o que contribui para se superar a circularidade que Zukin aponta no argumento do diferencial de renda. A despeito dessa semelhança, entretanto, há diferenças metodológicas notáveis no modo como esses dois autores abordam o tema das mudanças culturais, fazendo com que suas proposições assumam níveis de profundidade teórica e conteúdos políticos bastante distintos.

Se os modelos explicativos centrados no diferencial de renda têm o inconveniente de deixar em aberto o problema dos fatores constitutivos da renda potencial, cabe ressalvar que Ley, por sua vez, também deixa algumas perguntas sem respostas satisfatórias. Esse autor mostra-se curiosamente reticente quanto às origens das mudanças culturais que aponta como forças motrizes dos processos de gentrificação. Ley anuncia as mudanças culturais e 0 surgimento da cidade "criativa" como se tais fatores constituíssem acontecimentos espontâneos, variáveis independentes às quais não se cogita atribuir causas. Diferentemente de Harvey, para quem desvendar possíveis nexos entre as mudanças culturais e transformações mais abrangentes constitui uma preocupação central, Ley não chega a aventar a hipótese de que os novos hábitos urbanos, padrões estéticos e atividades econômicas que identifica possam ser desdobramentos de estratégias de reprodução do capital que atingem a vida social em sua totalidade. Não ocorre ao autor supor que as mudanças culturais que identifica possam ser apenas causas aparentes dos processos de gentrificação, e que, numa análise mais atenta, possam vir a se revelar fatores correlacionados ao referido fenômeno, mas movidos por causas mais distantes e menos evidentes.

0 tratamento das mudanças culturais como variáveis independentes conduz Ley a um discurso de teor ambíguo em relação à gentrificação. Embora se apresente como um crítico desse processo, o autor reconhece nos fatores que identifica como suas causas um sentido paradoxalmente positivo. A naturalidade com que utiliza expressões carregadas de juízos valorativos para diferenciar o atual contexto do anterior - como pode se observar no contraste entre o "modernismo muscular" da cidade industrial e o caráter "criativo" da 
cidade pós-industrial - deixa transparecer seu otimismo em relação às mudanças em curso, ainda que de modo implícito. Em meio a tal construção discursiva, a crítica à gentrificação fica reduzida à condição de alerta para um efeito colateral indesejável associado a um processo de transição para uma ordem social com padrões culturais e estéticos tidos como qualitativamente superiores. Esses novos padrões, entretanto, ficam de fora do escopo de sua crítica, dirigida pontualmente à gentrificação.

Embora admita a importância de analisar o papel das mudanças culturais em suas reflexões sobre a cidade contemporânea, diferentemente de Ley, Harvey mostra-se preocupado em entender suas origens, encarando-as como padrões socialmente produzidos. Explorando as mediações entre as mudanças culturais e as transformações no regime de acumulação do capital, o autor oferece uma base conceitual que permite interpretar as primeiras como fatores internos às segundas, não caindo numa autonomização dessas mudanças, como acontece com Ley. Essa postura permite ao autor elaborar um discurso crítico sobre os processos de gentrificação em sua totalidade, de modo que sua dimensão simbólica e sua dimensão material são vistas como momentos articulados e indissociáveis.

As formulações teóricas com ênfase na esfera da produção e da oferta, como as de Smith e Harvey - embora possam levar à simplificação de algumas mediações relativas aos padrões culturais que poderiam enriquecer as respectivas análises - trazem críticas de alcance mais amplo que as abordagens centradas prioritariamente na esfera do consumo e da demanda. Ao tratar as mudanças de padrões estéticos e hábitos de consumo como produtos e, ao mesmo tempo, aspectos funcionais de estratégias de acumulação do capital, essas perspectivas permitem desmistificar discursos sedutores e evidenciar seu papel ideológico, mostrando maior vigor como dispositivo de resistência à gentrificação no âmbito teórico.

\section{Conclusão}

Este artigo buscou contribuir para o avanço do debate teórico sobre a gentrificação a partir da contraposição de duas perspectivas distintas. De um lado, as teorias centradas na oferta (ou na produção), para as quais o diferencial de renda constitui o principal fator por trás dos processos de gentrificação. Do outro, as teorias centradas na demanda (ou no consumo), que atribuem preponderância às mudanças em padrões culturais e hábitos de consumo para explicar a dinâmica e a racionalidade subjacentes a tal processo. Enfatizou-se particularmente a obra de dois autores que acabaram se tornando referências emblemáticas de cada uma dessas perspectivas no debate internacional sobre o tema da gentrificação: Neil Smith e David Ley.

Para além de caracterizar esses dois modelos teóricos e apresentar seus principais pontos de divergência, buscou-se explorar possíveis pontos de contato entre eles. Adotando-se 0 argumento do diferencial de renda como fio condutor da análise, foram levantadas algumas considerações feitas por representantes das teorias centradas na demanda quanto a seus limites explicativos. A partir dessas críticas, foram apontadas algumas fragilidades 
no argumento do diferencial de renda que não constituiriam apenas objeções feitas com base em premissas metodológicas e propósitos de análise distintos, mas que seriam aspectos capazes de comprometer alguns dos objetivos das próprias teorias centradas na oferta.

A primeira ressalva discutida diz respeito à imprevisibilidade e à indeterminação dos focos de incidência dos processos de gentrificação. Mencionou-se a crítica de que o diferencial de renda constituiria um argumento excessivamente abstrato que não permitiria predizer onde, nem com que intensidade, os processos de gentrificação poderiam ocorrer, e de que haveria evidências empíricas contrárias às suposições das teorias centradas nesse conceito. Apoiando-se em estudos conduzidos por Eric Clark com o intuito de questionar essas críticas, argumentou-se que os testes empíricos que as fundamentam partiram de entendimentos equivocados acerca da noção de diferencial de renda, o que põe em xeque suas conclusões. Argumentou-se também que, ao ter como foco principal a investigação das causas comuns aos processos de gentrificação em geral, espera-se de antemão que as teorias centradas na oferta se atenham às especificidades de casos empíricos em menor grau que a outra corrente, e que tal característica é condizente com suas opções metodológicas. Por outro lado, reconheceu-se que a indeterminação espacial dos campos de incidência de processos de gentrificação constitui efetivamente um obstáculo ao alcance das próprias pretensões teóricas dos modelos explicativos centrados no argumento do diferencial de renda, e que essa objeção torna-se um aspecto particularmente sensível no momento em que Neil Smith alega que os processos de gentrificação tornaram-se um fenômeno generalizado em sua fase mais recente. Argumentou-se que essa hipótese, ao abrir margem para que se abarque sob esse termo qualquer exemplo de transformação do espaço urbano de caráter socialmente excludente, pode conduzir a um tratamento indiferenciado das frentes de expansão suburbana e do movimento de volta do capital aos centros, o que compromete a pretensão de identificar nexos entre mudanças no regime de acumulação do capital e a dimensão territorial dos modelos de desenvolvimento urbano.

A outra limitação do argumento do diferencial de renda discutida neste artigo diz respeito à explicação dos fatores constitutivos do descolamento entre a renda efetivamente capitalizada e a renda potencial. Partindo da crítica apresentada por Sharon Zukin quanto à circularidade desse argumento, apontou-se a falta de atenção dada à reflexão sobre os elementos capazes de provocar a elevação da renda potencial por parte das abordagens centradas na oferta como origem dessa lacuna. Foi sugerido que, embora o apontamento dos ciclos de realização e depreciação dos capitais incorporados ao ambiente construído dê conta de explicar as oscilações na renda efetivamente capitalizada, 0 argumento de que o crescimento da escala das cidades elevaria a renda potencial em seus centros, por sua vez, mostrou-se demasiadamente vago para explicar os fatores determinantes do segundo termo da hipótese do diferencial de renda, uma vez que esse argumento poderia ser usado para explicar a elevação da renda potencial em qualquer fragmento urbano, sendo insuficiente para fundamentar por si só a volta do capital aos centros. 
Argumentou-se que a incorporação de alguns aportes teóricos trazidos pelas abordagens centradas na demanda, particularmente a hipótese de David Ley acerca da conversão da estética num fator determinante para a valorização da propriedade urbana, permitiria que essas limitações fossem mitigadas, abrindo caminho para uma compreensão mais abrangente acerca dos fatores constituintes do diferencial de renda e para uma caracterização mais precisa dos campos de incidência dos processos de gentrificação e de seus ritmos. Nesse sentido, levantou-se a hipótese de que a defasagem entre o que David Ley (apoiado em Pierre Bourdieu) chama de capital simbólico e capital econômico seria um fator adicional aos ciclos de realização e depreciação do capital fixo e à ampliação da escala das cidades na constituição do diferencial de renda. Sugeriu-se que a combinação desses dois fatores em determinados fragmentos urbanos proporcionaria potenciais de valorização acima da média, tornando-os lugares especialmente suscetíveis a sofrer processos de gentrificação.

$\mathrm{Na}$ etapa final do artigo, recorreu-se a um conjunto de formulações de David Harvey para ilustrar como a exploração de mediações entre as esferas da produção e do consumo pode contribuir para a elevação do potencial explicativo de teorias sobre a gentrificação. Buscou-se concatenar uma série de proposições e argumentos apresentados por esse autor com o intuito de explorar possíveis caminhos para a articulação dos argumentos do diferencial de renda e das mudanças culturais. Ainda que o autor não tenha proposto uma síntese entre tais modelos explicativos nesses termos, buscou-se evidenciar como algumas de suas formulações teóricas poderiam contribuir para a construção desse raciocínio.

Apontou-se como ponto de convergência entre David Harvey e David Ley a identificação de uma tendência de atribuição de conteúdo econômico à dimensão simbólica das cidades como um traço característico do mundo contemporâneo. Diferenciou-se, entretanto, o modo como esses dois autores abordam essa questão. Afirmou-se que enquanto Ley trata as mudanças culturais como variáveis independentes, não conferindo maior atenção à reflexão sobre suas origens, Harvey aborda esse fenômeno como um fator interno a transformações mais amplas no regime de acumulação do capital, encarando-as não como acontecimentos espontâneos, mas como padrões socialmente produzidos. Por fim, argumentou-se que, ao observar o papel das mudanças nos padrões culturais e hábitos de consumo a partir dessa perspectiva, torna-se possível enxergá-los como momentos de uma estratégia específica de reprodução do capital, o que permite, por sua vez, entender melhor as mediações subjacentes a tal estratégia e formular críticas mais abrangentes sobre os processos de gentrificação.

\footnotetext{
Alvaro Luis dos Santos Pereira

Universidade de São Paulo, Faculdade de Arquitetura e Urbanismo, Laboratório Direito à Cidade e Espaço Público. São Paulo/SP, Brasil.

alvarosp@yahoo.com
} 


\section{Notas}

(1) "Gentrification is the process, I would begin, by which poor and working-class neighborhoods in the inner city are refurbished via an influx of private capital and middle-class homebuyers and renters - neighborhoods that had previously experienced disinvestment and a middle-class exodus. The poorest working-class neighborhoods are getting a remake; capital and the gentry are coming home, and for some in their wake it is not entirely a pretty sight" (Smith, 1996, p. 30). Smith chega a estabelecer uma diferenciação entre os processos de gentrificação e os novos desenvolvimentos imobiliários (redevelopment). Esse último processo envolveria a substituição do antigo parque imobiliário por novas edificações, enquanto o primeiro envolveria apenas a reabilitação e adaptação de edificações antigas, preservando o patrimônio arquitetônico remanescente e atribuindo-lhe novas funções e usos (Smith, 1982, p. 139). Ao longo de sua obra, entretanto, o autor não chega a se ater a tal diferenciação de modo sistemático, usando o termo gentrificação para fazer referência a situações em que, a rigor, estariam presentes esses dois fenômenos.

(2) "The rent gap is the disparity between the potential ground rent level and the actual ground rent capitalized under the present land use [...] The rent gap is produced primarily by capital devalorization (which diminishes the proportion of the ground rent able to be capitalized) and also by continued urban development and expansion (which has historically raised the potential ground rent level in the inner city)" (Smith, 1996, p. 65).

(3) "Evidence is entirely lacking in Canadian cities for the rent gap thesis; indeed, if anything, gentrification has occurred in inner cities with higher inner-city-CMA [census metropolitan area] house-price ratios" (Ley, 1986, p. 531).

(4) "The gap measured by Ley is that between inner city housing costs and that of metropolitan housing costs, which suggests that his test of the rent gap hypothesis is based on a misconception. He assumes the hypothesis to say that gentrification will take place where housing costs are lowest, when in fact the hypothesis states that the difference between potential land rent and capitalized land rent constitutes an economic force toward redevelopment and that redevelopment is therefore more likely to occur where this difference is greatest" (Clark, 1988, p. 245).

(5) "The fourth characteristic of this latest phase is the outward diffusion of gentrification from the urban center. This is far from a smooth or regular process, but as gentrification near the center results in higher land and housing prices, even for old, untransformed properties, districts further out become caught up in the momentum of gentrification" (Smith, 2002, p. 442).

(6) "Today the link between economic and geographical expansion remains, giving the frontier imagery its potency, but the form of that connection is very different. Economic expansion today no longer takes place purely via absolute geographical expansion but rather involves internal differentiation of already developed spaces. At the urban scale, this is the importance of gentrification vis-à-vis suburbanization. The production of space in general and gentrification in particular are examples of this kind of uneven development endemic to capitalist societies" (Smith, 1996, p. xviii).

(7) Cabe ressalvar que o argumento do diferencial de renda incorpora alguns elementos da economia urbana neoclássica. No entanto, diferencia-se dela em pontos fundamentais, tais como a distinção entre preço da terra e valor do capital incorporado ao espaço, o foco na oferta e não na demanda, o reconhecimento dos conflitos de classe como aspectos relevantes subjacentes aos processos de gentrificação e a tomada de uma postura crítica em relação a ele (ver Clark, 1988, p. 246). 
(8) "Much like a real frontier, the gentrification frontier is advanced not so much through the actions of intrepid pioneers as through the actions of collective owners of capital. Where such urban pioneers go bravely forth, banks, real estate developers, small-scale and large-scale lenders, retail corporations, the state, have generally gone before" (Smith, 1996, p. xviii).

(9) "The post-1990s generalization of gentrification as a global urban strategy plays a pivotal role in neoliberal urbanism in two ways. First, it fills the vacuum left by the abandonment of twentiethcentury liberal urban policy. Second, it serves up the central - and inner - city real-estate markets as burgeoning sectors of productive capital investment: the globalization of productive capital embraces gentrification" (Smith, 2006, p. 446).

(10) "This paper pursues some of the relations between art, aestheticisation and commodification in the residential landscape of the creative city [...] The case is not being made that an understanding of the aestheticisation of place is all that need to be known about the incidence of gentrification. However, I would argue that it opens some seminal ways of thinking about the restructuring of urban space in post-industrial cities, where the exaltation of representation over function is far from the ethos of the industrial city and its muscular modernism, glorified in the efficiency and utilitarianism of mass production" (Ley, 2003, pp. 2528-2529).

(11) "It is precisely this act of transformation that will be discussed in this paper, the movement of a product, and indeed a place, from junk to art and then on to commodity" (Ley, 2003, p. 2528).

(12) "The present argument in a nutshell is that the origins of gentrification included the establishment of an urban habitus that drew its identity from a perspective rich in cultural capital but (initially) weak in economic capital" (Ley, 2003, p. 2536).

(13) "A acumulação flexível foi acompanhada na ponta do consumo [...] por uma atenção muito maior às modas fugazes e pela mobilização de todos os artifícios de indução de necessidades e de transformação cultural que isso implica. A estética relativamente estável do modernismo fordista cedeu lugar a todo o fermento, instabilidade e qualidade fugidias de uma estética pós-moderna que celebra a diferença, a efemeridade, o espetáculo, a moda e a mercadificação de formas culturais" (Harvey, 1992, p. 148).

(14) "The macro-economic as well as local implications of urban entrepreneurialism and stronger inter-urban competition deserve some scrutiny. It is particularly useful to put these phenomena into relation with some of the more general shifts and trends that have been observed in the way capitalist economies have been working since the first major post-war recession of 1973 sparked a variety of seemingly profound adjustments in the paths of capitalist development. To begin with, the fact of inter-urban competition and urban entrepreneurialism has opened up the urban spaces of the advanced capitalist countries to all kinds of new patterns of development, even when the net effect has been the serial reproduction of science parks, gentrification, world trading centers, cultural and entertainment centers, large scale interior shopping malls with postmodern accoutrements, and the like [...] The shift in urban politics and the turn to entrepreneurialism has had an important facilitative role in a transition from locationally rather rigid Fordist production systems backed by Keynesian state welfarism to a much more geographically open and market based form of flexible accumulation. A further case can be made (cf. Harvey, 1989a and 1989b) that the trend away from urban based modernism in design, cultural forms and life style towards postmodernism is also connected to the rise of urban entrepreneurialism" (Harvey, 1989, pp. 11-12). 
(15) "To begin with, enquiry should focus on the contrast between the surface vigour of many of the projects for regeneration of flagging urban economies and the underlying trends in the urban condition. It should recognize that behind the mask of many successful projects there lie some serious social and economic problems and that in many cities these are taking geographical shape in the form of a dual city of inner city regeneration and a surrounding sea of increasing impoverishment" (Harvey, 1989, p. 16).

(16) Em termos bastante sintéticos, a acumulação primitiva consiste no processo pelo qual os produtores são separados dos meios de produção em virtude do estabelecimento de direitos de propriedade sobre os últimos e de seu controle por uma classe de proprietários, o que obriga os primeiros a vender a própria força de trabalho para poder satisfazer suas necessidades materiais num modo de produção baseado na troca mercantil e no trabalho assalariado. $\mathrm{Na}$ obra de Marx, esse processo é constitutivo das relações sociais em que se fundamenta o modo de produção capitalista.

(17) "A closer look at Marx's description of primitive accumulation reveals a wide range of processes [...] All the features that Marx mentions have remained powerfully present within capitalism's historical geography. Some of them have been fine-tuned to play an even stronger role now than in the past. The credit system and finance capital have, as Lenin, Hilferding and Luxemburg all remarked, been major levers of predation, fraud and thievery" (Harvey, 2003, p. 74).

\section{Referências}

BOURDIEU, P. (1984). Distinction. Cambridge/MA, Harvard University Press.

(1993). The field of cultural production. Nova York, Columbia University Press.

BUTLER, S. (1981). Enterprise zones: greenlining the inner city. Nova York, Universe Books.

BUTLER, T. (2007). Re-urbanizing London Docklands: gentrification, suburbanization or new urbanism? International Journal of Urban and Regional Reserch, v. 31, n. 4, pp. 759-781.

CLARK, E. (1988). The rent gap and urban change: case studies in Malmö 1860-1985. Geografiska Annaler, (B), v. 70, n. 2, pp. 241-254.

GLASS, R (1964). London: aspects of change. Londres, Centre for Urban Studies/MacGibbon e Kee.

HARVEY, D. (1989). From managerialism to entrepreneurialism: the transformation in urban governance in late capitalism. Geografiska Annaler (B), v. 71, n. 1, pp. 3-17.

(1992). A condição pós-moderna. São Paulo, Loyola.

(2003). The new imperialism. Oxford, Oxford University Press.

(2005). A produção capitalista do espaço. São Paulo, Annablume.

(2008). The right to the city. New Left Review, v. 53, pp. 23-40.

LASKA, S. e SPAIN, D. (1980). Back to the city: issues in neighborhood renovation. Elmsford, Pergamon Press. 
LEY, D. (1980). Liberal ideology and the postindustrial city. Annals of the Association of American Geographers, v. 70, pp. 238-258.

(1986). Alternative explanations for inner-city gentrification. Annals of the Association of American Geographers, v. 76, pp. 521-535.

(1987). The rent gap revisited. Annals of the Association of American Geographers, v. 77, n. 3, pp. $465-468$.

(2003). Artists, aestheticisation and the field of gentrification. Urban Studies, v. 14, n. 12, pp. 2527-2544.

LIPTON, G. (1977). Evidence of central city revival. Journal of the American Institute of Planners, n. 43, pp. 136-147.

PRYKE, M. (1991). An international city going global: spatial change in the City of London. Society and Space, n. 9, v. 2, pp. 197-222.

SLATER, T. (2011). "Gentrification of the city". In: BRIDGE, G. e WATSON, S. (eds.). The new companion to the city. Oxford, Blackwell.

SMITH, N. (1982). Gentrification and uneven development. Economic Geography, n. 58, pp. 139-155. (1987). Gentrification and the rent gap. Annals of the Association of American Geographers, v. 77, n. 3 , pp. $462-465$.

(1996). The new urban frontier: gentrification and the revanchist city. Londres, Routledge.

(2002). New globalism, new urbanism: gentrification as global urban strategy. Antipode. Nova York, v. 34, pp. 427-450.

(2006). "A gentrificação generalizada: de uma anomalia local a uma estratégia global”. In: BIDOU-ZACHARISIAN (org.). De volta à cidade: dos processos de gentrificação às políticas de "revitalização" dos centros urbanos. São Paulo, Annablume.

ZUKIN, S. (1987). Gentrification: culture and capital in the urban core. American Review of Sociology, n. 13 , pp. 129-147.

Texto recebido em 15/out/2013

Texto aprovado em 23/dez/2013 